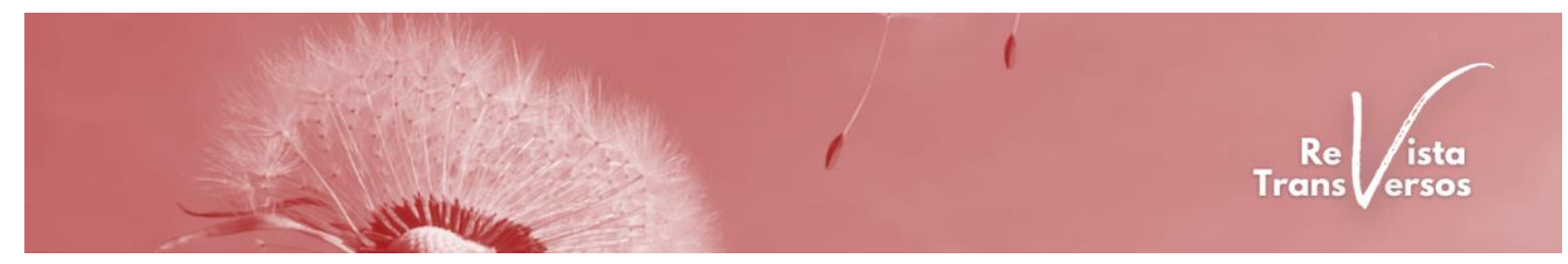

DOI: $10.12957 /$ transversos.2021.64210

\title{
OS DESAFIOS DA EDUCAÇÃO PARA A CIDADANIA \\ E DO ENSINO DA HISTÓRIA NA ESCOLA: UMA ENTREVISTA COM FRANÇOIS AUDIGIER ${ }^{1}$
}

\author{
Guilherme Moerbeck \\ Universidade do Estado do Rio de Janeiro (UERJ) \\ guilherme.gomes.moerbeck@uerj.br \\ Marc-André Éthier \\ Université de Montréal \\ marc.andre.ethier@umontreal.ca
}

François Audigier, Doutor em Didática, é Professor Honorário na Faculdade de Psicologia e Ciências da Educação da Universidade de Genebra².

Moerbeck/Éthier: Olá, professor François Audigier, é uma grande satisfação poder entrevistálo para o dossier da Revista Transversos - o futuro do passado: desafios para o ensino da história na escola numa perspectiva global.

François Audigier: Antes de mais nada, gostaria de vos agradecer o interesse demonstrado pelos meus trabalhos, bem como daqueles dos grupos aos quais inspirei. Durante meio século da minha vida profissional e pós-profissional, tratou-se sempre de trabalhos coletivos; as ideias, frequentemente produzidas no diálogo e no trabalho comum, são amplamente partilhadas.

As perguntas que me fazem exigem respostas complexas. As minhas serão, obviamente, parciais e provisórias. As questões e desafios atinentes ao ensino da história e da formação do cidadão ultrapassam largamente os limites deste exercício, pelo que peço ao leitor que seja indulgente com as aproximações que utilizo. Se algumas das minhas respostas estão diretamente ligadas às minhas experiências profissionais, outras são as de um "cidadão», certamente informado, mas não mais competente do que muitos sobre os problemas colocados pelo presente e pela construção de um futuro que esperamos comum para a humanidade.

\footnotetext{
${ }^{1}$ Tradução ao português: Guilherme Moerbeck.

${ }^{2}$ Cf. https://www.unige.ch/fapse/life/equipe/membres-associes/francois-audigier/
} 
Como introdução, proponho algumas observações e reflexões sobre temas presentes em várias das suas questões:

. Minhas respostas são construídas a partir de minhas experiências de ensino e pesquisa na França e depois na Suíça romanda. Para aquelas e aqueles que desejam prolongar as reflexões que reúno aqui, indico, quando pertinente, referências acessiveis na Internet, pedindo-lhes que desculpem o fato de quase todos estes textos estarem em francês.

- Várias das suas perguntas incidem quer sobre as relações entre ensino da história e educação para a cidadania, quer mais diretamente sobre a contribuição da história para a formação do cidadão. Note-se, para começar, que uma e outra sempre foram objeto de debates, frequentemente violentos. Por exemplo, após a Primeira Guerra Mundial, os professores ${ }^{3}$ franceses queriam suprimir o ensino da História, pois este tinha desenvolvido um sentimento nacionalista que havia conduzido à barbárie dos anos 1914-18. Mais francamente, ambas são diretamente instrumentalizadas pelos poderes, seja na Rússia, na China ou em muitos países muçulmanos, para não falar de alguns Estados europeus...

. Se, como todos os outros professores ou pesquisadores num domínio específico, aqueles que trabalham com a História, a formação cidadã e as suas didáticas são, em primeiro lugar, concernidas por estas últimas, nunca se deve esquecer que a Escola é uma instituição em perpétuas transformações. Ela é igualmente objeto de debates constantes entre grupos com concepções de educação e interesses diferentes, divergentes e mesmo conflitivos. Acrescento que, de um ponto de vista «interno», a Escola é também um lugar de confrontos entre disciplinas escolares que se autoproclamam indispensáveis às gerações futuras. Hoje, mais do que nunca, novas e importantes exigências sociais, mais diretamente ligadas à vida pessoal e coletiva e às urgências da nossa época, batem à sua porta. Essas assumem frequentemente um título do gênero «Educação para... », para o meio-ambiente, para os meios de comunicação social, para a saúde, para a paz... Isto acentua a concorrência entre as disciplinas escolares que pretendem poder responder a estas novas exigências e aos partidários da sua inserção explícita nos tempos escolares ${ }^{4}$.

\footnotetext{
3 Instituteurs - pessoa que ensina nas escolas da educação infantil e básica, progressivamente, a expressão foi substituída por enseignant ou professeur d'école [N.T.].

${ }^{4}$ Em português brasileiro diríamos mais "nas aulas", mas quis-se manter a ideia,mais ou menos implícita, de uma disputa entre as disciplinas por tempos na grade escolar [N.T.].
} 
Audigier, F. (2012). Les Éducation à...: Quels significations et enjeux théoriques et pratiques? Esquisse d'une analyse. Recherches en didactiques, 13, 25-38. https://www.cairn.info/revue-recherches-en-didactiques-2012-1-page-25.htm.

. As tarefas atribuídas à Escola são cada vez mais difíceis de delimitar e ainda mais de cumprir. Esta instituição torna-se um «lugar» de transmissão entre outros, muitas vezes mais eficazes, mais atraentes, mais próximo das gerações mais jovens. Tomarei o exemplo de uma corrente de pensamento da Califórnia para a qual é preciso suprimir os estudos que se figuram além de alguns campos essenciais, ler-escrever-contar-falar, e pôr os jovens o mais rapidamente possível em situações reais da vida.

. Várias das minhas respostas poderão ser interpretadas como fazendo parte de temáticas passadas, referência de um «velho» que tem algumas dificuldades em compreender as mutações das referências e dos modos de vida das «novas gerações». No entanto, olhando-se bem para isto, parece-me haver uma grande falta de memória nas pesquisas em matéria de educação em geral, de didática em particular. Estamos longe de um domínio nos quais "resultados" pudessem ser acumulados para que novas investigações lhes sejam baseadas. A minha impressão é que a investigação se constrói, sobretudo, em função dos contextos e das curiosidades do pesquisador ou do laboratório no qual está inserido. Além disso, as referências utilizadas e os temas de pesquisa são extremamente variados.

Audigier, F. (2001). Quelques questions à l'enseignement de l'histoire aujourd'hui et demain. Cartable de Clio, 1, 55-77. https://ecoleclio.hypotheses.org/files/2016/07/Clio1.pdf

Audigier, F. (2002). Un estudio sobre la ensenanza de la historia, la geographia y la educacion civica en la escuela elemental de Francia: temas, métodos y preguntas. Ensenanza de las ciencias sociales, 1, 3-16. http://www.raco.cat/index.php/EnsenanzaCS/article/view/126114/183014

. Para completar rapidamente esses apontamentos gerais, acrescento que, para descrever, analisar, compreender e interpretar o ensino e a aprendizagem em ação, em atos (que é o objetivo das didáticas), não se deve esquecer que se exercem vários poderes sobre os professores, muitas vezes fortes, tais como os poderes administrativos, dos diretores de escola, ${ }^{5}$ inspetores, ou ainda, muitas vezes, dos pais etc. Isto coloca os formadores universitários em concorrência com estes poderes, por exemplo, no que se refere à formação, tanto inicial como contínua.

\footnotetext{
${ }^{5}$ No original, “chefs d'établissements ", jargão mais utilizado na França. No Québec, por exemplo, predomina o termo directeur/directrice d'école, mais próximo ao uso da língua portuguesa no Brasil.
} 
Moerbeck/Éthier: Para os mais jovens que iniciam os seus estudos, é importante conhecer a trajetória das suas referências. Afinal, "há uma pessoa por detrás do nome”! Fale-nos um pouco da sua trajetória e, sobretudo, do que o atraiu para o universo do ensino e da didática da história. Quais são os professores que o inspiraram na sua carreira académica? O que inspirou a contribuição de pessoas como Henri Moniot ou Lucile Marbeau?

Audigier: Antes de transmitir algumas informações sobre a minha trajetória profissional, proponho breves marcos sobre as didáticas no mundo francófono, em particular na França.

No mundo francófono, as didáticas das disciplinas podem ser definidas como o estudo do ensino e da aprendizagem centradas nos conteúdos. Este último termo é «englobante», pois reúne tanto os saberes como os conhecimentos, as competências, os valores, as práticas etc. Isto diferencia-as de outras abordagens como a da sociologia ou da pedagogia, esta última mais centrada naquilo que os professores fazem. Mas estas distinções são arbitrárias e é indispensável estabelecer relações entre esses diferentes campos de investigação. Como compreender as diferenças entre o que faz um professor de história numa escola onde os alunos são provenientes de classes privilegiadas e o que faz aquele que ensina num meio desfavorecido sem entrecruzar as abordagens didáticas e as abordagens sociológicas? Os exemplos de atravessamentos ou de empréstimos que os didáticos fazem a outras ciências humanas e sociais - psicologia cognitiva, psicologia social, sociologia, antropologia, história da educação etc. - são numerosos e explicam, em parte, a grande diversidade dos trabalhos que se inscrevem no campo das didáticas.

$\mathrm{Na}$ França, mais especificamente, as didáticas das disciplinas nasceram por volta dos anos 1970, em relação às reformas de estrutura e de curriculum (na França, fala-se mais no termo programa) que acompanharam a ampliação do ensino até os 16 anos e, de fato, além disso, para maioria dos jovens. A matemática (com o conceito de transposição didática), o francês, as ciências da natureza (com o conceito de objetivo-obstáculo) foram as primeiras disciplinas em causa. Isto é interpretado também como a escolha das disciplinas tidas como as mais importantes ${ }^{6}$.

\footnotetext{
${ }^{6}$ Os conceitos que Audigier aborda acima ganharam seus horizontes desde o início da década de 1980 pelos estudos de Yves Chevallard para o caso da transposição didática no campo das ciências humanas, baseado em estudo anterior no campo da didática da matemática feita por Michel Verret em 1975. Menos conhecido no Brasil, especialmente entre os historiadores, estão os estudos que concernem ao conceito de objetivo-obstáculo, oriundos dos trabalhos seminais de Jean-Louis Martinand [N.T].
} 
É no Instituto Nacional de Pesquisa Pedagógica (INRP), vinculado ao Ministério da Educação Nacional, por iniciativa e sob a liderança de Lucile Marbeau, agregada ${ }^{7}$ de geografia e supervisora pedagógica regional, que os primeiros trabalhos de inovação sobre o ensino da história e da geografia tiveram início a partir dos anos 1970. Uma convicção forte, que teve e ainda tem muitas dificuldades em impor-se, é a de reorganizar os currículos destas disciplinas, tendo em conta a ampliação da escolaridade e, por conseguinte, os 9 ou mesmo os 12 anos de estudo a que estão sujeitos os alunos. Em outras palavras, a escola primária é um primeiro andar antes do ensino secundário. Este é constituído por um primeiro ciclo de 4 anos, o collège ${ }^{8}$, ao qual acedem, em princípio, todos os alunos. Segue-se um segundo ciclo diferenciado em três tipos de liceu'. Isso significava, especificamente, que era necessário pensar em conjunto estes nove anos de escola comum e construir o primário como uma preparação para o collège. Tradicionalmente, os alunos do primário percorriam toda a cronologia desde a pré-história até aos nossos dias, privilegiando a história da França. No collège, os alunos começavam a percorrer a linha do tempo. Para a história e a geografia, integrando de fato a educação para a cidadania, as equipes INRP conceberam e experimentaram programas complementares, tanto para estes dois níveis como para o liceu. Tratava-se também de ter em conta a idade dos alunos, por exemplo, a grande dificuldade deles em «imaginar» as longas durações, para não falar da complexidade das situações históricas que mesclam política, economia, social, cultural... (voltarei a esse ponto mais adiante). Para isso, os «social studies» nos Estados Unidos e os trabalhos do psicólogo Jerome Bruner foram inspirações fortes. Estas inovações e investigações foram sempre conduzidas e dirigidas em estreita relação com professores ditos «do chão da escola ${ }^{10}$ ». Os trabalhos do INRP, frequentemente criticados, nunca foram elucubrações de alguns iluminados isolados das realidades do ensino. $\mathrm{O}$ mesmo acontece sempre com a grande maioria das pesquisas em didática, mesmo que essas colaborações não sejam sempre apoiadas pelas autoridades administrativas. É também durante este período que são introduzidos os «objetivos» como forma de refletir diferentemente os

\footnotetext{
${ }^{7}$ Os professores agregés na França realizam um exame específico que lhes confere tal distinção. Em geral, os agregés são aqueles e aquelas que lecionam nas universidades ou lycées (este é sistema colegial francês, equivalentes aos CEGEPS no Québec ou aos colleges em países anglófonos - é, no entanto, inexistente no Brasil, no qual os alunos passam diretamente do Ensino Médio (parte do secondaire francês) às universidades por meio de vestibulares ou do ENEM) [N.T.].

${ }^{8}$ No original, collège quer-se dizer parte do sistema escolar francês que sucede o élémentaire (primaire) e antecede o lycée.

${ }^{9}$ Lycée - o mais próximo do que se pode chamar de o Ensino Médio no Brasil.

${ }^{10}$ Em francês, "du terrain" [N.T.].
} 
programas escolares, uma forma de pensar, inicialmente, em construir situações de ensino em função das aprendizagens que os alunos devem construir e não partir (apenas) dos saberes a ensinar.

Desde a sua criação em 1970-1971, a Universidade Denis Diderot, Paris VII, Universidade de vocação pluridisciplinar, acolheu um departamento de didáticas das disciplinas. Entre os professores, Henri Moniot, historiador especialista em África, participou na formação de doutoramento, em particular por meio da realização de um seminário em didática da história no âmbito de uma diplomação ${ }^{11}$ que precedia a tese. Henri Moniot não fez qualquer pesquisa didática no sentido estrito do termo, mas esteve sempre à escuta daqueles e daquelas que ali se engajavam. O seu olhar era vivo e crítico, convidando a pôr à distância afirmações insuficientemente fundamentadas. Gosto muito da sua fórmula para designar aquilo para que podiam servir as didáticas para os professores: «a raciocinar sobre o ensino». Não se trata, portanto, de dar receitas, do "pronto para ensinar ${ }^{12}$ ", mas sim de construir e propor instrumentos que os atores se apropriam para melhorar o seu ensino.

Num plano mais pessoal, após uma agregação em geografia (concurso em que a história está também presente, uma vez que, na França, os professores do ensino secundário ensinam história e geografia), juntei-me às equipes do INRP desde o início do ano letivo, em 1972, numa escola que acolhia todos os alunos e experimentava um ensino em grupos de nível para as matérias ditas principais. Em história e geografia, os grupos eram chamados semi-heterogêneos. Nunca esquecerei ter ensinado a uma dúzia de alunos de 12-13 anos numa turma do sexto ano, alguns dos quais estavam no limite do analfabetismo e todos numa situação de recusa escolar. Entre eles, uma menina bastante jovem defendia a ideia de que a prostituição a que se entregava, disso tomei ciência no decurso do ano, era muito melhor do que estudar na escola para um futuro totalmente incerto. Então, o ensino da história ou a cidadania...!! É também com fatos deste tipo na memória que sempre desconfiei das grandes declarações sobre o que as nossas disciplinas trazem de essencial e, portanto, de evidente à formação dos jovens, e de ser um «doador de lições». Algumas de minhas respostas às perguntas seguintes carregam o traço de tais experiências.

Durante toda a minha vida profissional, muitos autores acompanharam-me. São demasiados para os citar a todos. Entre os geógrafos: Philippe Pinchemel e o seu interesse pela

\footnotetext{
${ }^{11}$ Possivelmente, o autor se refere ao Diplôme d'études approfondies, tipo de certificação das universidades francesas, obtida ao termo do primeiro ano do 3 e cycle, isto é, o doutorado [N.T.].

12 "Prêt à enseigner", no Brasil dir-se-ia, no jargão escolar, "receita de bolo" [N.T.].
} 
história da geografia, François Durand-Dastès presente em Paris VII, Yves Lacoste e a sua visão muito política desta disciplina, Roger Brunet e as suas estruturas elementares das dinâmicas espaciais $^{13}$ que suscitaram um grande interesse entre os didáticos por volta dos anos 80 . Há também a Associação Francesa para o Desenvolvimento da Geografia e a Revista Espace-Temps, muitos dos quais organizadores se tornaram geógrafos reconhecidos, como Christian Grataloup ou Jacques Levy. Entre os historiadores, para além daqueles que estudam este ou aquele período, voltei-me mais fortemente para os historiadores da educação e para aqueles que refletiam em termos epistemológicos. Dentre os primeiros, André Chervel constituiu uma referência essencial com o conceito de «disciplina escolar» que explicarei mais adiante. Antoine Prost oferece análises aprofundadas e apaixonantes sobre a história do ensino, pondo em perspectiva, na duração, o número de escolhas institucionais e pedagógicas. Dentre os segundos, Henri-Irénée Marrou, injustamente esquecido, Paul Veyne ou, mais recentemente, François Hartog são referências obrigatórias. Reinhardt Koselleck com os seus trabalhos sobre os conceitos em história é absolutamente essencial (conferir adiante).

Para reunir as disciplinas que estudam as sociedades presentes e passadas, um sociólogo, Jean-Claude Passeron, mostra que todas estas disciplinas têm os mesmos fundamentos epistemológicos. Uma vez que qualquer estudo de uma situação social, presente ou passada, é necessariamente colocado no tempo, chama-lhes «ciências sócio-históricas». Os sociólogos da educação são também indispensáveis àquilo a que chamarei «didáticos contextualizados». Outras referências acompanharam-me, nomeadamente em torno do construtivismo com Ernest von Glasersfeld e a escola de Palo Alto com Gregory Bateson ou Paul Watzlawick.

E depois, como nem os historiadores, nem os geógrafos, nem os politólogos... dizem como os alunos, os indivíduos constroem, elaboram saberes em história, geografia ou cidadania, ou seja, como uns e outros se apropriam deles depois de os conhecerem na escola ou por intermédio de um ou outro meio de comunicação social, o didático deve procurar «noutro lugar» referências úteis, em particular no que concerne à psicologia cognitiva ou a psicologia social. Ainda a título de exemplo, Bruner, citado acima, foi uma referência constante; Vygotski um contributo essencial para a compreensão do que é um conceito e as relações entre pensamento e linguagens. Para estudar as maneiras como os indivíduos constroem seus conhecimentos, eu me voltei, como muitos didáticos, para a psicologia social com representações sociais a partir dos

\footnotetext{
${ }^{13}$ No original, chorèmes.
} 
trabalhos de Serge Moscovici. Depois de colocar as representações sociais como referência essencial para compreender as aprendizagens, completei gradualmente esta referência com tudo o que diz respeito à linguagem, às nossas categorias e ao seu manuseio, às generalizações, uma evolução cada vez mais marcada nas minhas preocupações, mas tão difícil de operar. Por fim, para não ser demasiado longo, há uma referência que me acompanha ao longo de todo o meu percurso, o filósofo Paul Ricoeur, sobre o qual volto mais adiante.

Audigier, F. (2005). Histoire de stéréotypes, stéréotypes sans histoire. Cartable de Clio, 5, 67 77. https://ecoleclio.hypotheses.org/files/2016/07/Clio5.pdf

Audigier, F. (2014). Histoire, géographie, citoyenneté : les moteurs clandestins du sens. Recherches en Didactiques, 18, 9-23. https://www.cairn.info/revue-recherches-endidactiques-2014-2-page-9.htm

Moerbeck/Éthier: Em muitos países do mundo, a relação entre o estudo da história e a formação cívica exprime formas de sinergia, mas também tensões entre diversas funções da educação. Em última análise, esta relação é sinérgica, conflituosa ou ambas ao mesmo tempo? Como você vê as experiências desta relação, História e formação de cidadãos, em diferentes países?

Audigier: Na medida em que publiquei um capítulo de uma obra de um editor brasileiro, sou bastante breve na minha resposta e acentuo alguns aspectos a debater.

AUDIGIER, F. (2016). História escolar, formação da cidadania e pesquisas didáticas. In: GUIMARÃES, S. (Org.). Ensino de história e cidadania. Campinas: Papirus Editora.

Sinergia e tensão? Ambos ao mesmo tempo. Estas tensões são, muitas vezes, ignoradas; mais precisamente, são conhecidas, mas para o bom andamento dos discursos sobre o ensino, é melhor fazer «como se...», como se isso fosse simples e evidente. Como muitas vezes em minhas respostas, eu dissocio para conectar melhor, cidadania em seguida, história.

Audigier, F. (2007). Enseignement de l'histoire et éducation à la citoyenneté - ouvrir un débat. Cartable de Clio, 7, 247-250.

https://ecoleclio.hypotheses.org/files/2016/07/Clio7.pdf

Audigier, F (2007). L'éducation à la citoyenneté dans ses contradictions. Revue internationale de l'éducation, Sèvres, 44, 25-34. http://ries.revues.org/125

Resisto a abordagens que declaram cidadão todo o indivíduo que vive numa sociedade. Pois a partir desse momento, tudo se torna cidadão e vertemos numa imprecisão absolutamente estéril. Eu defini a educação para a cidadania (EC) a partir de uma abordagem do cidadão como 
«titular de direitos e de obrigações em virtude da sua pertença a uma comunidade política» (é o passaporte que garante a cidadania e a pertença!). Por conseguinte, a EC é uma educação para o(s) direito(s) e para o(s) poder(s); a estes dois termos junta-se uma dimensão mais «afetiva» relativa à pertença a uma comunidade política, pertença que é simultaneamente um fato, um fato que exige conhecimentos sobre o que é esta comunidade, suas instituições e seu funcionamento, e um sentimento, uma adesão que se espera positiva.

A história (como a geografia para as sociedades do presente com toda a questão daquilo que é «presente»...) estuda todas as dimensões das sociedades pretéritas. Porque é simultaneamente «filha do seu tempo» e disciplina que coloca o presente, numa «longa duração», reivindica um lugar dominante na formação dos cidadãos, insistindo, em particular, na inscrição da comunidade política no tempo. Esta comunidade política é, na maior parte dos casos, tipificada sob o termo «nação», designação que abre imediatamente certezas para alguns, debates e conflitos para outros. A história constrói-se numa espécie de «teleologia dos territórios»; em outras palavras, os atuais Estados soberanos supostamente são o resultado, de certo modo natural, da História. Então, também a pertença é «natural». Em contrapartida, é muito mais marginalmente que ela estuda o que é oriundo do direito, exceto algumas abordagens dos regimes políticos; quanto aos poderes (não só políticos), ela trata-os constantemente (o que são as relações humanas, senão também as relações de poderes), mas não como um objeto de reflexão, e, portanto, de aprendizagem, sistemática.

Para o cidadão, o que importa, antes de tudo, é o seu presente e o seu futuro, os da $\mathrm{CP}^{14}$ a que pertence (não é bom ser «apátrida» ou refugiado). Daquilo que precede, sempre em linhas muito gerais, a história, acadêmica ou escolar, não pode ser a única referência, a única contribuição para a formação do cidadão. É claro que, nestes tempos de «presentismo» (Hartog), de incertezas e de preocupações em relação ao futuro, é absolutamente necessário um pensamento do tempo na longa duração ${ }^{15}$, não apenas para conhecer as formas como o nosso mundo foi construído, as dificuldades em que se encontra hoje e as que enfrentará amanhã, mas também para aprender a pensar temporalidades diferentes. Outro contributo é/seria colocar à distância muitos dos nossos esquemas «explicativos» que apresentam frequentemente um acontecimento,

\footnotetext{
${ }^{14}$ Comunidade Política [N.T.].

${ }^{15}$ No original, "temps long". Quis-se, aqui, dar emprestar um sentido de estudos de outras temporalidades, eventualmente numa longa duração (outras temporalidades) que possam forçar uma saída do presenteísmo. Em francês, é muito comum se encontrar a expressão "longue durée" no mesmo campo semântico.
} 
uma situação, como o resultado «obrigatório» do desenrolar histórico daquilo que o precede (ver: a ideia de teleologia). Esta vontade de explicação «racional» deixa demasiadas vezes de lado aquilo que depende da liberdade de decisão, liberdade dos indivíduos, liberdade dos poderes, sem esquecer o «acaso». Por fim, como as outras ciências sócio-históricas, mas, muitas vezes de forma mais intensa, a história ensina a necessidade da contextualização, da consideração da multiplicidade dos fatores. Todas essas considerações são contribuições primordiais para a formação do cidadão.

Audigier, F. (2002). L'éducation à la citoyenneté à la recherche de présences effectives. Revue suisse des sciences de l'éducation, 24, 2002, 3, 451-466. https://sjer.ch/article/view/4639

Moerbeck/Éthier: Nas últimas reformas nacionais, as que criaram uma base nacional dos programas escolares no Brasil (BNCC), a disciplina de história tornou-se a protagonista de um longo debate. De certa forma, isto recorda-nos as reflexões de Christian Laville sobre as guerras de narrativas (1999). É interessante notar que a história antiga e medieval se tornou objeto de uma verdadeira batalha: alguns pensavam que os temas destas temporalidades deveriam ser excluídos do programa, enquanto outros, ao contrário, apoiavam a permanência deles. Por um lado, alguns criticavam a história antiga e medieval por traduzirem uma experiência centrada na Europa e por terem ocupado espaços que poderiam ser dedicados à história brasileira. Por outro lado, alguns outros afirmavam que a história antiga poderia ser ensinada para suscitar a alteridade e criticar o próprio eurocentrismo. Como você compreende essas tensões que fazem parte dos debates sobre os programas escolares e que assumem proporções que vão muito além do próprio campo científico? Em suma, será que estudar a história do seu próprio país é uma garantia da criação de uma visão crítica da própria sociedade entre os jovens?

Audigier: Como já foi dito, a questão do «nacional» foi sempre objeto de debate em história, tal como acontece no espaço público. Nunca teremos terminado com tal questão; nunca será estabilizada. Estudar a história do seu país nunca foi uma garantia «crítica». Numerosos exemplos mostram-nos a mobilização da história ao serviço dos poderes instalados neste ou naquele Estado, para não falar do «ensino da história dos vencedores» para parafrasear Christian Laville.

Eu retomo esta interrogação sobre os programas e o nacional nas minhas respostas à pergunta 5. Assim sendo, se a história antiga e medieval tem uma conotação «europeia», salvo erro da minha parte, as sociedades existem há alguns milhares de anos, tanto no continente 
americano como na África e na Ásia. Então, são possíveis outras opções. E se considerarmos útil uma abertura aos outros, estes dois períodos também tiveram sociedades e civilizações muito interessantes a serem estudadas para se abrir a alhures e a outrem.

No entanto, aproveito esta pergunta sobre os programas escolares para recordar um princípio da realidade: na quase totalidade dos sistemas educativos, o ensino da história desenrola-se num ou dois tempos do horário semanal dos alunos. Sejamos ainda mais realistas, um período que não é de uma hora (de curso), mas sim de 50-55 minutos e todo esse tempo não é inteiramente útil para a aprendizagem. Na maioria dos casos, o ano letivo dura cerca de 35-40 semanas. Para permanecer na França e no collège: a totalidade dos períodos históricos (e a totalidade do espaço planetário para a geografia) estão disponíveis para construir programas num período de 4 anos. As escolhas são necessariamente extremamente limitadas e a cultura transmitida e construída cheia de «buracos». Assim, a continuidade cronológica na história é uma armadilha! (ver: Audigier 2001).

Moerbeck/Éthier: Num capítulo intitulado «História escolar, formação da cidadania e pesquisas didáticas», publicado no Brasil em 2016, você afirmou: «Toda disciplina escolar é organizada e funciona, ao mesmo tempo, com as suas próprias modalidades que combinam o que lhe impõe a forma escolar e de acordo com o que lhe é próprio» (Audigier, 2016, p. 41). Você acha que há falta de diálogo entre a área da investigação nas universidades e as práticas cotidianas nas escolas? Podemos pensar numa epistemologia própria da forma escolar da história?

Audigier: A sua pergunta tem dois conceitos diferentes: forma escolar, disciplina escolar. Apresento rapidamente os dois.

«Forma escolar» é um conceito elaborado por um sociólogo que retoma trabalhos de historiadores da educação para descrever o modo de organização da Escola e a relação dos saberes em relação ao modelo de socialização em numerosos países. Esta forma estabelece um quadro que assegura uma direção ao ensino e, por conseguinte, as aprendizagens.

Audigier, F. (2005). Les enseignements d'histoire et de géographie aux prises avec la forme scolaire. In : Maulini, O. et Montandon, C. (éd.), Les formes de l'éducation: variété et variations. Raisons éducatives, 9. Bruxelles: de boeck, 103-122. 
https://www.unige.ch/fapse/publications-ssed/files/5714/1572/5506/FOREDU-INTMaulini.pdf

Audigier, F. (2008). Formes scolaires, formes sociales. Un point de vue de didactiques des sciences sociales - histoire, géographie, éducation à la citoyenneté. Babylonia, 3/08, 8-13. http://babylonia.ch/fileadmin/user_upload/documents/2008-3/audigier3 01.pdf

Por «disciplina escolar», retomo a formalização feita por André Chervel, citado anteriormente, para descrever a disciplina «francesa» como uma construção própria da Escola destinada prioritariamente à aprendizagem da leitura, da escrita e da ortografia (grosso modo); são estes objetivos que determinam a forma e o conteúdo da disciplina ensinada. Este põe em evidência a necessidade de pensar uma disciplina escolar não como uma simplificação/adaptação de saberes acadêmicos, mas como uma construção própria da Escola para responder às finalidades que são as desta disciplina. Por isso, há a necessidade de pensar numa epistemologia própria da história escolar. O professor constrói conteúdos de ensino que devem ser «ensináveis», isto é, levar em conta, em particular, horários e idade dos alunos, "possível de ser aprendida» por estes, «mensuráveis», uma vez que as aprendizagens devem ser avaliadas. (A avaliação é um campo bastante pobre em nossos didáticos).

Audigier, François 2012h. Que valent les apprentissages de citoyenneté, de géographie et d'histoire? In Leininger-Frézal, C., Ogier, A. et Genevois, S. Actes du colloque sur les didactiques de l'histoire, de la géographie, de l'éducation à la citoyenneté, Lyon, INRP 2010. 408. 429.

\section{https://www.unige.ch/fapse/edhice/files/1114/2496/8295/actes lyon 2011.pdf}

Esta epistemologia não é evidentemente independente daquela da história acadêmica e é impossível, ou mesmo inaceitável, pensar nela sem referência a esta última. Mas pensar a autonomia da história escolar convida a dar conta de maneira mais rigorosa das características próprias desta história. Por exemplo, se a construção de um problema de pesquisa histórica não pode ser feita sem um estado da $\operatorname{arte}^{16}$, o mesmo não acontece com os alunos. A problematização será necessariamente diferente; para a compreensão das aprendizagens e a solidez da sua avaliação, é importante analisar estas diferenças. Eu poderia fazer a mesma observação para os trabalhos, muitas vezes muito interessantes sobre a construção de narrativas pelos alunos ou sobre a distinção história/memória. Mas, muitas vezes, estou em uma expectativa não cumprida das análises, de se considerar a diferença/distância entre as práticas dos universitários, de pesquisas

\footnotetext{
${ }^{16}$ No original: "état de la question".
} 
que inspiraram estes trabalhos e do que é realmente realizado na sala de aula, aprendido e construído pelos alunos.

Com o objetivo de caracterizar as disciplinas escolares, história e geografia, uma análise dos programas franceses desde o século XIX levou-me a agrupar as suas finalidades em torno de três conjuntos. Das finalidades cívicas e políticas para transmitir e construir um sentimento de pertença à uma comunidade política. $\mathrm{O}$ que não impede que estes programas sejam abertos aos «outros». Das finalidades intelectuais e críticas. Estas disciplinas ensinam maneiras de pensar e de escrever, capacidades de análise, de exame crítico dos documentos, de síntese etc. Elas fazem parte na formação da inteligência e da razão. Das finalidades práticas, menos imediatas, mas os textos oficiais ${ }^{17}$ são sempre empregados a mostrar a sua importância na vida pessoal e social.

Acaso estes três conjuntos de finalidades permaneçam válidos, o seu equilíbrio mudou fortemente. As finalidades cívicas e políticas são sempre afirmadas essenciais, mas cada vez mais delicadas de operar num contexto pluricultural, de abertura ao mundo, de transformação do trabalho e de "crise da democracia». Desde os anos 70, que se põe em destaque aquilo a que eu chamei uma «caixa de ferramentas» com a definição de noções e conceitos, a aprendizagem de métodos de trabalho, em particular sobre os documentos, a aprendizagem de referências no tempo e no espaço.

Esta análise levou-me também a formalizar um modelo deste ensino que chamei «modelo republicano» em torno de quatro características, os «4R». Ao apresentá-los, acrescento por qual razão cada «R» se diferencia da história acadêmica.

A história (e a geografia) escolar funciona com:

- O ensino de um Referente consensual. Ensinar uma história que unifique e rejeite o debate, versus uma história acadêmica plural que se articula no debate entre os pares, ou mesmo além;

- Um ensino baseado nos Resultados da pesquisa. Ensinar o que é admitido em um determinado momento, o que é suficientemente estabilizado, versus a busca de novas questões, novas fontes, novos métodos;

- Uma concepção Realista do conhecimento. “As palavras são as coisas”, versus uma distância crítica, por exemplo em relação às palavras e conceitos, formulações e categorias que usamos e que são construções sociais.

\footnotetext{
${ }^{17}$ Tudo leva a crer que o autor se refira aos programas escolares emanados dos ministérios da educação, quando fala em "textes officiels".
} 
- A Recusa da política e das divergências ${ }^{18}$, versus a explicitação dos posicionamentos e das referências epistemológicas. pelos pesquisadores.

Audigier, F. (1995). Histoire et géographie : des savoirs scolaires en question; entre les définitions officielles et les constructions des élèves. Spirales, 15, 61-89. http://www.spiraleedu-revue.fr/IMG/pdf/3 AUDIGIER Spi15.pdf

Audigier, F. (1997). Histoire et géographie, un modèle disciplinaire pour penser l'identité professionnelle. Recherche et Formation, 25, 9-22. http://ife.enslyon.fr/publications/edition-electronique/recherche-et-formation/RR025-02.pdf

Audigier, F. (1992). Pensar la geografica escolar. Un repte per a la didàctica. Barcelone: Documents d'Analisi Geogràphica, 15-33. http://www.raco.cat/index.php/DocumentsAnalisi/article/view/41556.

Audigier, F. (1999). School disciplines, social representations, and the construction of the didactics of history, geography, and civics. Instructional Science, 27, 97-117. Repris dans The Didactics in the Francophone World, Kluwer academic publishers, Dordrecht, NL. https://link.springer.com/article/10.1023/A\%3A1003074224963

Quando se estuda «O Antigo Egito» em 6 ou 10 tempos de aula, segundo a divisão horária com alunos do início do secundário ${ }^{19}$, $11-12$ anos (é preciso respeitar a ordem cronológica!), cria-se uma «vulgata», ou seja, uma sequência de temas que encontramos (quase) em todos os manuais e que (quase todos) os professores introduzem: o Nilo, a religião, a preservação dos mortos, a arquitetura, a escrita... Tudo isto tirado de um Egito que dura cerca de 3000 anos e que é ensinado como um todo que não muda...

Moerbeck/Éthier: Recentemente, Benoît Falaize (2014) chamou a atenção para os "temas controversos” na França. No Brasil, no mesmo sentido, Fernando Seffner e Nilton Mullet Pereira (2018) falavam de “passados vivos e temas sensíveis”. Ambos, mutatis mutandis, tocam de maneira crítica as pretensões narrativas universalistas de um "romance nacional”; mas, vão além disso, pondo em evidência dimensões ligadas ao racismo, à homofobia e aos temas que

\footnotetext{
${ }^{18}$ Os grifos são do tradutor.

${ }^{19} \mathrm{O}$ autor utiliza mais a palavra collège para se referir ao equivalente segundo segmento do fundamental. Note-se, outrossim, que no Québec, o secondaire engloba o que seria o somatório dos fundamental II e parte do Ensino Médio no Brasil. Na França, o secondaire é o somatório do período do collège (12-15 anos) com o lycée (16-18 anos). Tanto o Lycée na França quanto os CEGEPS (também chamado de colleges) no Québec preparam para a formação técnica profissional e/ou para a entrada nos cursos universitários. É bom lembrar que no Brasil, embora não seja predominante, há formações técnicas em Nível Médio, como é o caso das Escolas Normais e de segmentos escolares mais especializados como o caso das FAETEC's, CEFET's no Estado do Rio de Janeiro e de escolas técnicas federais. A educação no Brasil, em muitos aspectos tributárias da estrutura francesa, utilizou termos como colegial para designar o atual Ensino Médio [N.T.].
} 
mobilizam as aspirações da juventude francesa e brasileira em torno de suas memórias. Até que ponto podem ou devem os professores de história abordar a dimensão de um passado tão presente?

Audigier: Há vários temas de reflexão na vossa pergunta: a permanência ${ }^{20}$, o romance nacional, a universalidade, os temas controversos.

Eu desconfio muito da expressão "romance nacional" no que ela tem de sistemático para designar e desvalorizar uma narrativa que estaria obrigatoriamente de acordo com o ponto de vista do poder instalado. Nada obriga este romance a ignorar os conflitos sociais, o papel das migrações, as relações de força que estão na origem deste ou daquele acontecimento, as decisões catastróficas ou vergonhosas tomadas no passado etc. $\mathrm{O}$ "nacional" designa o fato de que o ponto de vista adotado, pois há sempre um ponto de vista, uma interpretação, é o de uma comunidade política, dita nacional, da sua constituição em direção à sua perenização. Mas isto nada diz sobre os contornos e os conteúdos desta comunidade política. Tudo depende do que os cidadãos (e os poderes) decidem sobre esses contornos e conteúdos.

Eu não tenho a certeza de que o "romance nacional" tenha qualquer pretensão universalista! A universalidade coloca-se a outro nível, o que tem uma relevância para o conjunto dos seres humanos. Impõem-se imediatamente os direitos humanos. Sejam quais forem as controvérsias de que são objeto e as reticências a se considerar como referência universal, são a única construção disponível que pode servir de fundação a um mundo comum para o conjunto dos habitantes do Planeta. A proclamação da igualdade de direitos e da igual dignidade de todos os seres humanos não têm nada de "natural"; é um combate constante que diz respeito a todas as sociedades, desde que aceitem esta proclamação.

Quanto ao termo "romance", ele sugere que se trataria de uma espécie de "ficção" à distância da história como "ciência". Mais uma vez, abre-se um vasto mundo de debates no qual não darei conta nos limites desta entrevista. Todavia, retenhamos do termo "romance", a ideia de um texto que narra, associando assim história e narração segundo a demonstração magistral de Paul Ricoeur. Sem dúvida, também, seria útil pensar com mais frequência, nos nossos ensinamentos, no prazer do texto». Diversão da história como experimentamos o prazer do romance!

\footnotetext{
${ }^{20}$ Literalmente, o que é retido - "le retiens".
} 
Os "temas controversos" são muito diversos. Há os que você menciona. Há os que exprimem mais intensamente uma relação com o futuro. Questão importante que especifico nas minhas respostas às perguntas seguintes.

Moerbeck/Éthier: Afinal, quem são os assassinos da memória? A menção ao livro de Pierre Vidal-Naquet (2005) é importante para fazer-se a pergunta de como se encara o passado e como ele se traduz em algo instrutivo e relevante para os alunos jovens. Em resumo, estamos perante uma questão da atualidade: os perigos do negacionismo. Como você imagina que as gerações que estão na escola podem lidar com fenômenos políticos perturbadores, como Le Pen, Trump, Bolsonaro? A escola e o ensino da história podem constituir uma mediação para questões políticas tão presentes e sensíveis na sala de aula? Poderá a educação para a cidadania ajudar a proteger os jovens dos discursos perversos, como as fake news?

Vou reunir as minhas respostas às perguntas 6 e 7.

Moerbeck/Éthier: Ainda segundo Vidal-Naquet, "Creio no dever da história, que só pode alimentar uma memória autêntica" (2005, p. 7). A memória (oficial, fragmentada, partilhada, subalterna, esquecida) faz parte de estratégias discursivas onde o passado é lido a partir do presente. Como diria R. Koselleck (2006), mas também Paul Ricœur (2000): o "tempo histórico” permanece entre horizontes de expectativa e espaços de experiências. Qual é o papel da escola, especialmente do professor de história, na abordagem destas memórias como temas escolares para preparar os jovens a estabelecerem uma boa relação em face da quantidade incomensurável de informação que circula nas redes sociais e na Internet em geral?

Audigier: Convido a ampliar o objeto, a partir das perguntas sobre o negacionismo ou a memória autêntica, no sentido da dimensão das escolhas que se deve fazer nos conteúdos ensinados. Já a apresentei uma vez que é essencial, mas ela merece ser aprofundada. Coloco-o sob a autoridade de Emmanuel Kant que, nas suas "Reflexões sobre a educação”, escreve: “As crianças não devem ser educadas apenas de acordo com o estado atual da espécie humana, mas baseado num estado futuro possível e melhor, ou seja, de acordo com a ideia da humanidade e o seu destino total". Leio este enunciado como a exigência de conceber a formação, a educação e a instrução dos 
alunos (os três são indissociáveis!) e de construir os currículos em função da ideia que se faz do mundo de amanhã.

Audigier, F. (2009). Compréhension du monde actuel et enseignements de l'histoire, de la géographie et de la citoyenneté. Prismes, 11, 10-13. https://www.hepl.ch/files/live/sites/systemsite/files/unitecommunication/prismes/numeros-complets/prismes-numero-11-2009-hep-vaud.pdf)

Evidentemente, o "negacionismo" e as "fake news" que infectam e corrompem o nosso mundo devem ser combatidos vigorosamente. Mas pergunto-me muitas vezes se não é necessário, para sermos ouvidos e compreendidos, tomar caminhos oblíquos. A adesão a estas perigosas ignomínias não estão assentadas num uso da razão, numa relação crítica e informada do mundo. Ela é altamente emocional, afetiva, até mesmo identitária. Temo que não seja propriamente eficaz demonstrar a mistificação presente nestas correntes. Outrossim, defendo mais a ideia de estudar situações e problemas que são urgências de outro tipo e desenvolver, a partir desses estudos, competências intelectuais e críticas. Por exemplo, isso não é muito original! As alterações climáticas ou a queda da biodiversidade são questões fundamentais para o futuro. É manifesto que, sobre tais temas, se pode trabalhar com os alunos as diferenças entre o que se sabe, o que os cientistas sabem e sobre os quais existem "provas" e o que permanece objeto de pesquisa. Ao designar estas questões ou dúvidas por "objetos de pesquisa”, trata-se de se fazer a separação entre as opiniões, as "fake News" e a investigação precisa, fundamentada, sobre estes objetos, examinar os fatos, confrontar os pontos de vista, levantar problemas, debater, mas não de uma forma qualquer.

Quanto aos temas para os quais os indivíduos estão mais "fechados" nas suas certezas e emoções, defendo que os estudemos, quer porque os currículos os exigem, quer porque eles vêm dos alunos ou dos professores num determinado momento do seu percurso de formação. Esta é uma oportunidade para reinvestir nas habilidades intelectuais e nas críticas construídas durante o estudo de outros temas. Retomando a formulação da pergunta, o nosso objetivo não é tanto o de "proteger" os alunos, mas sim o de "formá-los". O mundo é uma grande exposição que é descrita e compreendida pelas linguagens. A ciência, e, portanto, os ensinamentos científicos, especialmente os das ciências sócio-históricas, põem ordem nessa exposição, uma ordem racional.

Os temas que se impõem a nós sobre o futuro do planeta são numerosos: alterações climáticas, desigualdades sociais crescentes, deflagração de um mundo bipolar, confrontos China- 
USA, esgotamento de numerosos recursos, sociedade de consumo, universalidade de direitos humanos versus diversidade de valores, interrogações sobre a democracia que não é de modo algum evidente...

No entanto, sei bem que este ponto de vista se depara com evoluções mais profundas com a afirmação pública das emoções pessoais e coletivas, o declínio dos debates públicos argumentados e que respeitam os outros etc. Sim, o assunto é tão urgente como difícil! Contra a ideia de que temos acesso imediato a todo o conhecimento, a toda a informação, a todo o mundo... é urgente aceitar não se conhecer tudo, não estar constantemente ligado à espera desta ilusão do "tudo acessível", resistir à economia da atenção que a capta para melhor nos controlar, tornar o mundo indisponível como reflete o sociólogo alemão Hartmut Rosa... Mas já estou fazendo uma digressão!

Eu retorno à contribuição da história, contribuição indispensável, e os leitores desta entrevista estão, sem dúvida, convencidos disso. Recordo brevemente dois argumentos: a aprendizagem das temporalidades diferentes, em particular a da longa duração, a exigência de contextualização. A história também nos oferece muitas oportunidades para comparar situações, eventos. Certamente, tanto uns quanto outros são sempre singulares; todavia, para os analisar e compreendê-los, o espírito humano procede sempre pela comparação com o que já se sabe. As comparações são também o momento de reconhecer as identidades múltiplas, de não fechar cada um dentro de um "nós” fechado, diferente quiçá mesmo hostil aos outros.

No que diz respeito ao vínculo com a memória coletiva o dever de história é claro. No entanto, resisto ao adjetivo "autêntico". As memórias são plurais, descontínuas; o tempo histórico está cheio de "buracos". Compreendo a sua utilização e até a sua necessidade em muitos debates públicos nos confrontamos com mentiras, falsas verdades. Prefiro o reconhecimento 'crítico' da pluralidade das memórias, a pesquisa paciente e contínua para identificar o que é "verdadeiro" e o que é "falso", em vista da pluralidade das histórias e da construção de um mundo comum. Tudo isto está relacionado com os debates atuais em torno das "identidades”. Uma observação complementar a propósito do negacionismo: não se deve ignorar um fenómeno bem conhecido que é o do "esquecimento" progressivo do passado na memória coletiva. Três gerações? Neste verão de 2021, na França, vemos ressurgir expressões antissemitas em algumas passeatas de 
manifestantes. Como se a consciência ou o conhecimento do holocausto tivessem sido banidas durante algum tempo e, assim, algumas expressões voltassem a ser possíveis ${ }^{21}$.

Por fim, uma vez que vocês evocam as fórmulas de Koselleck retomadas por Ricoeur, esclareço que este último lhe acrescenta o "presente da iniciativa", que é o tempo da responsabilidade dos cidadãos. São três fórmulas muito bonitas que nos convidam a olhar para o passado, para os passados, como ao presente, aos presentes, com a liberdade dos seres humanos, liberdade individual, liberdade coletiva. Elas convidam-nos também a articular essas três dimensões do tempo nas nossas reflexões e ações.

Moerbeck/Éthier: No decurso das duas últimas décadas, houve debates sobre o pensamento histórico (Vilar, 1987) e as suas diferentes dimensões: a empatia (Lee, 2003), a consciência histórica (Rüsen, 2001), a perspectiva histórica (Vansledright, 2010; Wineburg 2001) a pertinência da dimensão conceptual e heurística (Carretero e Lopez, 2009), etc. Essa dimensão teórica chama a atenção para um tipo de "olhar histórico" e para o conjunto das metodologias e da análise das fontes que fazem parte da própria profissão do historiador. É possível encontrar na escola um equilíbrio entre pensar uma história a partir do estudo de suas narrativas e das habilidades intelectuais a serem desenvolvidas? Você vê limites para esta abordagem de aprendizagem por competências ou mais benefícios?

Audigier: Desta questão, destaco principalmente o que diz respeito às "competências" em relação à importância da formação intelectual e crítica. Para resumir, competências nos diz que o que é importante na vida é poder enfrentar as situações em que cada ser humano se encontra imerso, em que vive, age etc. Para isso, cada um deve dominar saberes no sentido mais amplo do termo, conhecimentos factuais, uma espécie de enciclopédia de situações que lhe permitem distinguirse, saber-fazer etc. Não se pode, portanto, opor saberes e competências.

É certo que, uma vez dito isto, verifico que há de novo grandes ambiguidades. Se o objetivo é construir as situações de ensino como, e em primeiro lugar, situações de aprendizagem e colocar as intenções de aprendizagem no centro das primeiras, sim. Se se trata de pensar o

\footnotetext{
${ }^{21}$ Essa última oração, no original: «Comme si la conscience ou la connaissance de la Shoah après avoir été bannies pendant un certain temps, de telles expressions redevenaient possibles ».
} 
ensino em função de competências que estariam unicamente ao serviço de uma formação profissional ligada à "empregabilidade”, não.

No entanto, competências e saberes levantam a muito antiga questão da organização dos currículos. Convém organizar os currículos segundo as lógicas próprias de cada disciplina e pressupor a transferência dos saberes assim ensinados nas situações da vida? Ou convém estudar tais situações e introduzir, para tal, os saberes necessários a esse estudo, como outras tantas contribuições para a construção de competências?

Quanto à relação entre competências, história e narração, para ser breve, parece-me que Paul Ricoeur "definitivamente" resolveu a questão. Toda a história assume a forma de uma narrativa, toda a história das ações humanas é uma narrativa. Por isso, compreender/construir uma narrativa é também uma competência! Toda a formação em competências ocorre necessariamente em situações, casos, exemplos... Não se trata de uma questão de "equilíbrio".

Aproveito esta pergunta para afirmar a necessidade de, na formação dos professores, dar (um pouco) lugar à história do ensino, em especial ao da história escolar, uma formação que não se limite ao ensino de fatos históricos, períodos históricos acompanhados de algumas palavras ditas pedagógicas para operacionalizar a transmissão aos alunos.

Audigier, F. (2000). Histoire, géographie et éducation civique : trois disciplines aux prises avec la diversité narrative. Repères, 21, 121-141. http://ife.ens-lyon.fr/publications/editionelectronique/reperes/INRP RS021 7.pdf

Moerbeck/Éthier: Henri Moniot afirmou a relevância "[de] levar progressivamente os alunos a reconhecerem o que são a história crítica e a história interiorizada, a viverem conscientemente os seus dois jogos, a compreenderem as suas exigências diferentes e a sua ligação insustentável” (1986, p.196). Moniot talvez chame a atenção para um elemento incontornável na dimensão humana, o das identidades e heranças na aprendizagem escolar. No entanto, há outros pesquisadores que problematizam a dimensão social do conflito. No que diz respeito a este assunto, Yves Lenoir chama a atenção aos perigos de uma: "adesão ao modelo social em vigor (...) de aceitar os valores, as normas e as regras sociais...” (Lenoir, 2014, p. 307). Como se organiza a disciplina escolar de História entre estas duas perspectivas? Existe um equilíbrio entre as suas duas grandes questões da teoria social - a coesão e o conflito social? 
Audigier: Sim, as identidades e as heranças fazem intrinsecamente parte do ensino e de toda a aprendizagem escolar, especialmente na história. Aprender história na escola é, simultaneamente, aprender história no sentido dos fatos históricos e aprender como a história-narração constrói esses fatos. A história escolar joga em ambos os registros de adesão e distanciamento.

A sua pergunta abre um novo tema, nomeadamente os valores. Ensinar inclui sempre valores, valores nos saberes ensinados, valores nas práticas de ensino, valores na condução do pessoal escolar, na primeira linha dos quais se colocam os professores. A presença dos valores é consubstancial a qualquer propósito, toda narrativa, que diz, que narra as sociedades e as ações humanas presentes, passadas e futuras. Para retomar Koselleck, esta presença está no próprio núcleo dos conceitos utilizados, no próprio núcleo da linguagem, da língua. Koselleck insiste fortemente, as "palavras", os conceitos abrem possibilidades, maneiras de fazer perguntas ao real e de compreendê-lo, enquanto fecha outras.

Audigier, F. (1991). Enseigner la société, transmettre des valeurs; former des citoyens, éduquer aux droits de l'homme : une mission ancienne, des problèmes permanents, un projet toujours actuel. Revue Française de Pédagogie, 94, 37-48. http://www.persee.fr/doc/rfp 0556-

$\underline{7807 \quad 1991 \text { num } 94 \quad 1 \quad 1365}$

Em relação aos perigos assinalados por Yves Lenoir, importa reafirmar um carácter fundador da democracia que não deve ser limitado às eleições. A democracia é o (único) regime político que faz da aceitação e da resolução dos conflitos um elemento essencial da coesão de uma comunidade política democrática pluralista e de sua dinâmica. Evidentemente, esta posição colide imediatamente com numerosas realidades nas quais (constantemente?) grupos sociais se esforçam em monopolizar poderes. No entanto, mais uma vez, convém repetir e trabalhar estas características através do estudo de situações históricas adequadas. Estas não faltam!

Moerbeck/Éthier: Numa entrevista que você concedeu a Jean-François Cardin no Bulletin du Crifpe (2009), o senhor mencionou: "Comecemos por recordar que, desde sempre, a escola teve uma finalidade de educação e não apenas de instrução”. Apoiantes do Governo Bolsonaro, durante vários meses, pretenderam criar um tipo de ensino supostamente mais objetivo, "pretensamente sem ideologias". O projeto "Escola sem partido" previa uma dicotomia entre a instrução e a educação. Em que é que esta dicotomia, imaginada pelos partidários da extrema direita brasileira, comporta perigos para o estudo da história e para a educação à cidadania? 
Audigier: Parece-me que muitas palavras ditas ao longo de todo este encontro respondem claramente a esta questão. Esta divisão entre educação/instrução não tem sentido em si. As duas estão totalmente ligadas. Ela pode ser útil para ajudar a pensar a Escola, o ensino, a formação e sua complexidade. Eu começo o artigo de 1991 afirmando não duas, mas três missões da Escola: instruir, educar, socializar. Mas não se pode decidir se se vai implementar uma em vez da outra. Assisti em demasia a debates deste tipo para não estar convencido da sua presunção. Uma Escola que seja apenas um lugar de instrução é um mito, um mito perigoso, já que nega as outras dimensões do ensino, de toda a prática docente. Para não falar de uma história escolar que seria uma espécie de verdade "absoluta". Ainda menos para a formação do cidadão! Aqueles que o proclamam defendem, de fato, o monopólio do seu pensamento. Penso ter desenvolvido várias vezes esta ou aquela reflexão sobre as exigências de rigor, sobre a importância dos saberes, do conhecimento para não ser acusado de me limitar apenas à "educação”. Aliás, o que é que isso quer dizer?

Moerbeck/Éthier: Em sua opinião, quais desafios se colocam ao ensino da história na escola em uma perspectiva global?

Audigier: Parece-me que, ao longo das minhas respostas, antecipei largamente a sua pergunta. Poderia desenvolver quase sem fim muitas delas. Permito-me deslocá-la, afirmando simultaneamente a contribuição insubstituível da história escolar para a formação do cidadão e a modéstia do que podemos fazer com os alunos, uma modéstia esclarecida, uma modéstia resoluta...

Moerbeck/Éthier: Se um estudante lhe pedisse para mencionar apenas um artigo sobre o ensino da história e da cidadania, qual seria a sua sugestão?

Audigier: Eu seria muito pretensioso. Numa bibliografia muito abundante e diversa, limitar-meei às minhas próprias publicações, deixando ao leitor o cuidado de escolher entre as que citei em eco a este ou àquele tema. 
Muito obrigado, Professor Audigier, lhe somos muito gratos.

\section{Referências}

AUDIGIER, F. História escolar, formação da cidadania e pesquisas didáticas. In: GUIMARÃES, S. (Org.). Ensino de história e cidadania. Campinas: Papirus Editora, 2016.

CARDIN, J.-F. Rencontre avec François Audigier. Bulletin du Crifpé, v. 16, n. 1, p. 11, mar. 2009, p. 9-16.

CARRETERO, M.; LÓPEZ, C. Estudios cognitivos sobre el conocimiento histórico: aportaciones para la enseñanza y alfabetización histórica. Enseñanza de las ciencias sociales : revista de investigación, p. $75-89,2009$.

LAVILLE, C. A guerra das narrativas: debates e ilusões em torno do ensino de História. Revista Brasileira de História, v. 19, n. 38, p. 125-138, 1999.

LEE, P. Nós fabricamos carros e eles tinham que andar a pé - compreensão das pessoas do passado. In: Educação histórica e museus: actas das 2as Jornadas Internacionais de Educação Histórica. Braga: Universidade do Minho, 2003, p. 19-36.

LENOIR, Y. L'enseignement des sciences humaines et sociales au primaire : face à la déliquescence de l'humain et du social, vers une reconceptualisation épistémologique des fondements. In: LAROUCHE, M.-C. ; ARAÚJO-OLIVEIRA, A. (Org.). Les sciences humaines à l'école primaire québécoise: regards croisés sur un domaine de recherche et d'intervention. Québec (Québec) : Presses de L’Université du Québec, 2014. p. 301-327.

MONIOT, H. Didactique de l'histoire. In : Dictionnaire des sciences historiques (Dir.). André Burguière, Paris, PUF, 1986.

RÜSEN, J. Razão Histórica. Edição : 1 a ed. Brasília : UNB, 2001.

VANSLEDRIGHT, B. A. The Challenge of Rethinking History Education. Edição: 1 ed. New York: Routledge, 2010.

VIDAL-NAQUET, P. Les assassins de la mémoire: "Un Eichmann de papier" et autres essais sur le révisionnisme. Ed. rev. et augm ed. Paris: Découverte, 2005. (La Découverte poche Essais, 201). VILAR, P. Penser historiquement. In : PENSER HISTORIQUEMENT, juillet 1987, Ávila. Anais... Ávila: [s.n.], juillet 1987. 
WINEBURG, S. Historical Thinking and Other Unnatural Acts: Charting the Future of Teaching the Past. Philadelphia: Temple University Press, 2001.

\section{Sobre os autores:}

Guilherme Moerbeck: Professor Adjunto da área Teoria, Historiografia e Ensino de História da Universidade do Estado do Rio de Janeiro, bem como do ProfHistória e PPGH ambos na UERJ. É Licenciado em História (2004); mestre (2007) e doutor (2013) em História Antiga pela Universidade Federal Fluminense (UFF). Possui pós-doutorado em Ensino de História na FGVRio (2015); em Arqueologia Clássica no Museu de Arqueologia e Etnologia (USP - 2019) e em Educação na Université du Québec à Montréal (UQÀM - 2021). Teve passagens como colaborador em pesquisa arqueológica em Delos organizada no âmbito da École française d'Athènes (EfA); Visiting research fellow no Departamento de Estudos Clássicos da Brown Univesity, assim como pesquisador associado nas Faculdades de Educação da Université de Montréal - UdeM e da UQÀM. Coordena o Didaskō - Grupo de Estudos em Ensino da História Antiga LEDDES/UERJ. Além disso, colabora em pesquisas nos: CRIFPE - Centre de recherche interuniversitaire sur la formation et la profession enseignante (UQÀM); LABECA - Laboratório de Estudos sobre a Cidade Antiga - MAE/USP; na COMUM - Comunidade de Estudos da Teoria da História - UERJ e no LAHUD - Laboratório em Rede de Humanidades Digitais (IBICT). Trabalhou durante 14 anos no ensino fundamental e foi destaque no Prêmio Professores do Brasil em 2018. É autor de artigos na área de Ensino de História; Educação; História Antiga e Teoria da História e dos livros Guerra, Política e Tragédia na Grécia Clássica (2014); Entre a Religião e a Política: Euripides e a Guerra do Peloponeso (2017); um dos organizadores do Antigas Leituras: Ensino de História (2020).

Marc-André Éthier: Formado em História (bacharelado e mestrado, Université de Montréal UdeM) e em Didática (doutorado em Didática, UdeM). Ensinou história no ensino médio, foi professor na Université du Québec à Trois-Rivières e, desde 2004, é professor na UdeM. É membro de diversos grupos de pesquisa, entre os quais o DiSEC (Diversité scolaire et l'éducation à la citoyenneté) e o CRIFPE (Centre de recherche interuniversitaire sur la formation et la profession enseignante). É também presidente do Comité d'agrément des programmes de formation à l'enseignement (CAPFE). As suas pesquisas foram financiadas pelo FRQSC e pelo CRSH. Estas pesquisas incidiram sobre a análise de conteúdo dos programas e dos manuais de história. Há alguns anos, elas incidem sobre o uso que os professores e os alunos fazem dos meios didáticos, como os manuais, os romances, os longas-metragens de ficção, os jogos de videogames de história ou nos artefatos e arquivos, bem como sobre as aprendizagens dos alunos em história e, em particular, sobre as que dizem respeito aos procedimentos de pesquisa em história. Marc-André Éthier é ainda o editor-chefe da Revue des sciences de l'éducation.

Artigo recebido para publicação em: 7 de dezembro de 2021. 
Artigo aprovado para publicação em: 13 de dezembro de 2021.

\section{Como citar:}

MOERBECK, Guilherme; ÉTHIER, Marc-André. Os desafios da educação para a cidadania e do ensino da História na escola: uma entrevista com François Audigier. Revista Transversos. Dossiê: O futuro do passado: Desafios para o Ensino da História nas escolas numa perspectiva global. Rio de Janeiro, no. 23, 2021. pp. 15-39. Disponível em: <https://www.epublicacoes.uerj.br/index.php/transversos/article/view/64210>. ISSN 2179-7528. DOI: $10.12957 /$ transversos.2021.64210

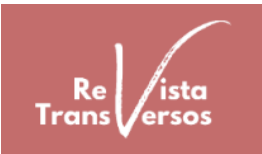

